\title{
First report of Sphingomonas sp. causing bacterial leaf blight of rice in Benin, Burkina Faso, The Gambia, Ivory Coast, Mali, Nigeria, Tanzania and Togo
}

\author{
K. Kini ${ }^{1}$, R. Agnimonhan ${ }^{1}$, R. Dossa ${ }^{1}$, B. Soglonou ${ }^{1}$, V. Gbogbo ${ }^{2}$, I. Ouedraogo ${ }^{3}$, K. Kpemoua ${ }^{4}$, M. Traoré ${ }^{5}$ and D. Silue $^{1 *}$
}

${ }^{1}$ AfricaRice, 01 B.P. 2031, Cotonou, Benin; ${ }^{2}$ Service Protection des Végétaux et Contrôle Phytosanitaire, Direction de I'Agriculture, 01 BP 58, Oganla, Porto-Novo, Bénin; ${ }^{3}$ INERA Bobo-Dioulasso, Burkina Faso; ${ }^{4}$ Institut Togolais de Recherche Agronomique (ITRA), B.P. 1163, Lome, Togo; ${ }^{5}$ Institut d'Economie Rurale (IER), BP 16, Sikasso, Mali

*E-mail: D.Silue@cgiar.org

Received: 27 Mar 2017. Published: 06 Jun 2017. Keywords: Oryza sativa, partial 16S rRNA gene sequence

Surveys of rice growing areas were conducted from 2011 to 2015 with the aim of assessing the importance of bacterial diseases in Benin, Burkina Faso, The Gambia, Ghana, Ivory Coast, Mali, Niger, Nigeria, Senegal, Tanzania and Togo. Between 100 to 500 samples showing symptoms consistent with leaf blight were collected from each country. Symptoms included yellow-brown discolourations along one of the two leaf blades, turning brown to dark-brown with age (Fig. 1). Severely affected leaves developed necrotic patches and died.

Diseased leaf sections were surface-sterilised, crushed in sterile water and the resulting sap subjected to a multiplex polymerase chain reaction developed to identify Xanthomonas oryzae pathovars (Lang et al., 2010). Of the approximately 4,000-5,000 samples tested, only 100-120 were positive using this assay (from samples collected in Benin, Burkina Faso, Mali and Niger). All sap samples were plated on peptone sucrose agar (PSA; $10 \mathrm{~g}$ peptone, $10 \mathrm{~g}$ sucrose, $15 \mathrm{~g}$ bacto agar, $50 \mathrm{mg}$ actidione, $40 \mathrm{mg}$ cephalexin and $20 \mathrm{mg}$ kasugamycin per litre distilled water) for strain isolation purposes. From the samples negative for the Xanthomonas oryzae assay, a 279 bp amplicon from the 16S rRNA gene was obtained for 604 isolates. These isolates were obtained from samples collected in Benin, Burkina Faso, The Gambia, Ivory Coast, Mali, Nigeria, Tanzania and Togo. Eight of the isolates were randomly selected and sequenced for further study. The isolates had $90.2-100 \%$ sequence identity to each other and analysis using BLASTn indicated that the eight isolates had 95 to $98 \%$ sequence identity with the $16 \mathrm{~S}$ rRNA gene from many type strains of Sphingomonas species including S. paucimobilis (GenBank Accession No. KP814059), S. melonis (EU429948) and S. zeae (NR_136793). The 16S rRNA standard approximation likelihood ratio tree created using Phylogeny.fr (Dereeper et al., 2008) showed that these isolates belong to Sphingomonas sp. but not to a specific species (Fig. 2). Seven of the sequences were deposited in GenBank: KT729520 (isolate ASP3, Benin), KT729521 (ASP6, Benin), KY630528 (ASP160, Togo), KY630529 (ASP283, Cote d'Ivoire), KY630530 (ASP360, Mali), KY630531 (ASP361, Mali), KY630532 (ASP447, The Gambia).

To assess pathogenicity, bacterial suspensions $\left(10^{8} \mathrm{CFU} / \mathrm{ml}\right)$ were prepared from pure cultures grown overnight on PSA plates. Inoculation of 35-dayold Oryza sativa seedlings was conducted on several rice accessions including C101A51, Azucena and Kitakea. Inoculations were performed by infiltrating leaves with the inoculum using a needleless syringe. The inoculated plants were kept in a greenhouse at $27 \pm 5^{\circ} \mathrm{C}$ and $80 \%$ relative humidity. Sterile distilled water served as a negative control. Initial disease symptoms appeared five days after inoculation (DAI), the leaf blade turned yellowish above the inoculation point and this progressed towards the leaf tip (Fig. 3). Blighted leaves, brown to dark-brown necrosis on the entire leaves above and sometimes below the inoculation point, were observed 15-21 DAI on susceptible rice accessions (C101A51, Azucena and Kitakea). Water-inoculated control plants remained symptomless. Symptoms on inoculated leaves resembled those found in the field. Analysis of the 16S rRNA gene partial sequences of the re-isolated bacteria showed that they were identical to the inoculated isolates, thereby fulfilling Koch's postulates. Comparison of the sequences obtained from the reisolated strains with those of the wild isolates showed $99-100 \%$ identity.

This is the first report of a leaf blight disease of rice caused by Sphingomonas sp. in Africa. Sphingomonas species have frequently been isolated from rice seed (Midha et al., 2016) and have been found on leaves of 26 plant species of 11 families but few are recorded as plant pathogens. Sphingomonas melonis, is the causal agent of a brown spot disease on fruits of Cucumis melo (Buonaurio et al., 2001) and Sphingomonas sp. causes bacterial leaf blight of Paliuris spina-christi (Deldavleh et al., 2013), The present report seems to be the third case of a plant disease caused by a member of this genus.

\section{Acknowledgements}

This research was funded by the Global Rice Science Partnership (GRiSP) and the Ministry of Foreign Affairs, Japan. Ms. T. Afolabi collected and maintained some of the isolates.

\section{References}

Buonaurio R, Stravato VM, Cappelli C, 2001. Brown spot caused by Sphingomonas sp. on yellow Spanish melon fruits in Spain. Plant Pathology 50, 397-401. http://dx.doi.org/10.1046/j.1365-3059.2001.00571x

Deldavleh M, Bahmani K, Harighi B, 2013. Bacterial leaf blight of Christ's thorn in Iran: a new disease caused by Sphingomonas sp. Journal of Plant Pathology 95, 75-78.

Dereeper A, Guignon V, Blanc G, Audic S, Buffet S, Chevenet F, Dufayard JF, Guindon S, Lefort V, Lescot M, Claverie JM, Gascuel O, 2008. Phylogeny.fr: robust phylogenetic analysis for the non-specialist. Nucleic Acids Research 36, W465-W469. http://dx.doi.org/10.1093/nar/gkn180

Lang JM, Hamilton JP, Diaz MGQ,Van Sluys MA, Burgos MRG, Vera Cruz CM, Buell CR, Tisserat NA, Leach JE, 2010. Genomics-based diagnostic marker development for Xanthomonas oryzae pv. oryzae and $X$ oryzae pv. oryzicola. Plant Disease 94, 311-319.

http://dx.doi.org/10.1094/PDIS-94-3-0311

Midha S, Bansal K, Sharma S, Kumar N, Patil NP, Chaudhry V, Patil PB, 2016. Genomic resource of rice seed associated bacteria. Frontiers in Microbiology 6, 1551. http://dx.doi.org/10.3389/fmicb.2015.01551

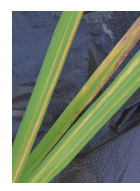

Figure 1

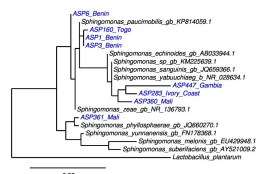

Figure 2

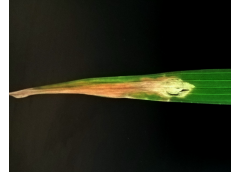

Figure 3

To cite this report: Kini K, Agnimonhan R, Dossa R, Soglonou B, Gbogbo V, Ouedraogo I, Kpemoua K, Traoré M, Silue D, 2017. First report of Sphingomonas sp. causing bacterial leaf blight of rice in Benin, Burkina Faso, The Gambia, Ivory Coast, Mali, Nigeria, Tanzania and Togo. New Disease Reports 35, 32. http://dx.doi.org/10.5197/j.2044-0588.2017.035.032 